\title{
LA TRANSCENDENTALIDAD COMO FUNDAMENTO DE LA METAFÍSICA DE ZUBIRI
}

\section{TRANSCENDENTALITY AS THE BASIS OF ZUBIRI'S METAPHYSICS}

\author{
José MANUEL LÓPEZ GARCÍA* \\ UNED
}

\begin{abstract}
RESUMEN: Desarrollo mis argumentaciones acerca de los vínculos y relaciones entre la esencia y lo transcendental y sobre cómo la metafísica intramundana de Zubiri se basa en la transcendentalidad, entendida como impresión de realidad. Esto supone un nuevo punto de partida para una metafísica que surge con la reflexión sobre el problematismo de la realidad y no simplemente en la pura especulación abstracta, y tiene como consecuencia la posibilidad de un transcendentalismo estético que comprenda la riqueza de lo real desde perspectivas más diversas y enriquecedoras. Considerando que como ya se sabe desde el deconstruccionismo derridiano es posible la superación de ciertos límites semánticos del lenguaje. Algo que se reafirma con una lógica del discurso que se fundamenta en una hermenéutica que admite una considerable flexibilidad en la especulación metafísica.
\end{abstract}

Palabras Clave: Transcendentalidad, transcendental, metafísica, realidad, intramundana, impresión.

ABSTRACT: I develop my arguments about the linkages and relationships between the essence and that which is transcendental and how Zubiri's wordly metaphysics is based on transcendentality, understood as a sense of reality. This a new starting point for a metaphysics that appears with the reflection on the problematism of reality, not merely from abstract speculation, and results in the possibility of an aesthetic transcendentalism that understands the richness of reality from different, enriching perspectives. We do this considering, as we know from Derrida's deconstructionism, that it is possible to overcome the semantic limits of language. This is confirmed by a

* Dirección postal del autor: Plaza de Europa, n 17, $9^{\circ}$ dcha. Gijón 33205 (Asturias)— Email: jmanuelp_58@hotmail.com 
logic of discourse that is based on a hermeneutics that allows considerable flexibility in metaphysical speculation.

KEYWORDS: Transcendentality, transcendental, metaphysics, reality, wordly, impression.

\section{Esencia y transcendentalidad}

Ciertamente una de las contribuciones principales de la filosofía de Zubiri ha sido la construcción de un realismo transcendental radical creado mediante un procedimiento descriptivo y fenomenológico original. En este sentido a diferencia de los planteamientos idealistas de la filosofía kantiana, hegeliana, etc., se observa que la metafísica intramundana de Zubiri se basa fundamentalmente en lo transcendental entendido como realidad en impresión .Indudablemente existe otro término zubiriano que requiere de una mayor explicitación: la transcendentalidad, que es la excedencia de la realidad respecto a su contenido o lo físico de la forma o formalidad de realidad. Y como la esencia es el sistema constitutivo de notas de cada cosa real, se comprende que lo esencial y lo transcendental están completamente integrados desde un planteamiento ontológico y gnoseológico, como es lo característico de la noología zubiriana.

El término «transcendo» está compuesto de «trans» o más allá y «scando» que en latín significa subir o escalar y de este modo es natural que ya los escolásticos llamasen transcendental al concepto que se predica de todas las cosas. El nuevo sentido y aplicación proporcionados a este vocablo metafísico por Zubiri es muy coherente a mi juicio, porque si bien sigue en la línea de desarrollar diferentes tipos de transcendentales, considero que lo principal o lo fundamental es su uso vinculado tanto a una ontología realista como a una teoría del conocimiento o noología también basada en una aprehensión de lo real a través de la intelección sentiente. Es utilizando una comparación con la etimología del termino transcendencia, como la averiguación de lo que es el mundo o la realidad desde una perspectiva que no es concipiente ni logificadora como sucede con el idealismo y el racionalismo, ya que se fundamenta en una metafísica intramundana o realista.

Desde un enfoque descriptivo, metafísico y fenomenológico, la filosofía zubiriana es inmensamente interesante y provechosa ya que el mismo Zubiri 
utilizaba una metododología que describía la realidad en todas las facetas que él podía investigar, creando un sistema filosófico grandioso, que tiene una de sus bases precisamente en la transcendentalidad y en la esencia entendida también como transcendente. Y evidentemente uno de los innumerables méritos de la filosofía zubiriana es precisamente el situar lo transcendental como fundamento tanto de la ontología como de la antropología, la religión y en general de todas las partes de la filosofía. Esto lo considero necesario si se pretende alcanzar, un pensamiento más unido a la propia realidad y también a la ciencia, si bien se ha de tener en cuenta la diferencia entre la reflexión filosófica y los procedimientos científicos. Lo que Zubiri logra es la confirmación de la justificación de la transcendentalidad como fundamento de todas las elaboraciones metafísicas que son creables o construibles por cualquier filósofo. En definitiva, el radical realismo fenomenológico transcendental zubiriano es la expresión de una actitud realista espontánea que ya surgió en Zubiri al principio de su filosofar y que se fue consolidando en los distintos periodos de su pensamiento. En este sentido es natural que a lo largo de su producción filosófica, en obras como Problemas fundamentales de la metafísica occidental y en otras, la contrastación con los pensamientos de otros filósofos sea esencial para la delimitación de sus ideas y sobre todo para la descripción y elaboración de su sistema de pensamiento. Aunque este ya es original por sí mismo, porque parte de la potentísima capacidad creativa de Zubiri y de su extraordinaria sutileza reflexiva y de pensamiento, aunque como lo transcendental es la realidad en impresión para Zubiri, se sobreentiende que en el proceso perceptivo y aprehensor del intelecto se siente, se piensa o se intelige la realidad de forma directa tal como es en sí misma, sin mediaciones representativas artificiales que dificulten el acceso inmediato a lo real. Por esta razón está justificado pensar que la transcendentalidad es el fundamento de una metafísica que tiene que ser intramundana, dirigida a la factualidad de las cosas, de lo fenoménico y también a la fisicidad de las cosas reales o al sistema constitutivo de notas que son las esencias tal como las define y comprende acertadamente Zubiri. Frente a la teorización aristotélica en relación con la ousía, que se refiere a la cosa, se impone una interpretación de la sustancia o esencia más bien como un sistema de notas necesarias para la realidad sustantiva de cada cosa. Y como es evidente, frente a la distinción entre sustancias primeras y segundas propuestas por Aristóteles, estoy convencido que independientemente de su valor heurístico y doctrinal que no niego, es mejor y es más apropiada al estado de la ciencia y la filosofía contemporánea una interpretación transcendental y por 
tanto realista de la sustancia o la esencia. Ya que como escribe López García ${ }^{1}$ en relación con el planteamiento antropológico de Zubiri: «El hombre, que está abierto a su realidad, no sólo se hace a sí mismo, sino que hace su realidad. En esto consiste realizarse.»

De esta manera es perfectamente entendible que Zubiri se posicione en contra o en clara y rotunda discrepancia con el idealismo absoluto de Hegel, porque es cierto que niega la posibilidad de un enfoque realista del conocimiento como el que afirma el filósofo español. Si bien es necesario reconocer que Hegel pretende estar más allá de estas dualidades. La negación de cualquier forma de logificación y entificación de la realidad por Zubiri, considero que la suya es la vía correcta para una rigurosa consideración de lo que es la realidad del mundo. En vez de comprender lo real como forma o modo de ser, que es lo característico del pensamiento escolástico en su indudable entificación de lo real, la aprehensión impresiva y sentiente de lo real es lo que da una dimensión transcendental al conocimiento y consecuentemente una radicalidad mayor a la inteligencia humana en su captación sentiente de lo fenoménico o real ya que pienso que la famosa proposición hegeliana, lo real es racional y viceversa, es enormemente discutible, aunque también es cierto que la esencia y su manifestación coinciden en el final de la Lógica de la esencia ya que para Hegel lo realmente real es racional o bien la igualdad entre lo especulativo y lo material, algo que a mi juicio, no se cumple o en todo caso es claramente refutable, si se considera y analiza desde un planteamiento descriptivo y metafísico como es auténticamente la realidad, algo que puede ser corroborado desde una perspectiva de análisis fenomenológico que no es el husserliano. Indudablemente, el logicismo hegeliano es contradictorio con una consideración del intelecto, que está en relación directa e inmediata con la realidad. Además conviene señalar que Zubiri indica que cualquier forma de logificación de la inteligencia representa la negación de un enfoque realista y transcendental de la metafísica y por tanto de la totalidad de la filosofía.

Que lo transcendental se vincula más a lo real que a lo puramente especulativo, es una consecuencia necesaria del planteamiento factual de la aprehensión en la metafísica intramundana zubiriana, lo que me parece perfectamente cohe-

${ }^{1}$ López GArcía, J. M. (2007). José Gaos y la filosofía coetánea. Ediciones Eikasía, pág, 110. 
rente y concordante con una visión o concepción de la filosofía más interrelacionada con la ciencia y con la tecnología. De esta forma lo sensitivo o sensorial adquiere una mayor significación en la teoría del conocimiento y aparece otro factor que posee una gran relevancia que son las categorizaciones producidas por el propio intelecto, que están inevitablemente influidas o condicionadas por la realidad que el propio sujeto conoce. Y esto me parece que es lo más adecuado en la construcción de cualquier sistema filosófico, aunque éste pueda describir la realidad y los aspectos de la misma que considere más relevantes, ya que son elaborables sistemas realistas diferentes y también diversas cosmovisiones de pensamiento que valoren lo que es la realidad y su transcendentalidad esencial, como estructura real que debe ser valorada en la especulación y reflexión filosófica.

La construcción del sujeto trascendental o del yo pienso en la teoría del conocimiento kantiana, es uno de los fundamentos de su idealismo epistemológico, pero a mi juicio es discutible al menos, porque la relación al pensamiento o al tener conciencia de lo percibido es inmediata y no precisa de mediación representativa. En este sentido la filosofía transcendental zubiriana es la plasmación de una comprensión de que el «yo pienso» no es la condición pura de nuestros pensamientos, porque en realidad no existe una dicotomía radical entre el sentir y el pensar o inteligir como considera Kant. Estimo que el apriorismo propio del sistema kantiano responde a unos procedimientos metafísicos que derivan en buena medida del ambiente filosófico característico del siglo XVIII en Alemania y en Europa. La influencia sobre todo del pensamiento de Leibniz, Descartes, Wolff, Baumgarten, etc. Está presente en las obras de Kant. En contraposición a estos planteamientos conciencialistas en relación con la cuestión de lo transcendental Zubiri elabora una metafísica transcendental claramente unida a la realidad con una compleja terminología que describe fenomenológicamente los múltiples niveles de interconexión existentes entre la inteligencia y la realidad aprehendida.

Que lo transcendental: «está dado con todo contenido de sentido» como indica Pìntor Ramos ${ }^{2}$ clarifica cómo entiende Zubiri la función de la intelección sentiente, que ya está en una línea de integración completa de lo intelectivo con

\footnotetext{
${ }^{2}$ Pintor Ramos, A. (2006). Nudos en la filosofía de Zubiri. Salamanca: Univ. Pontificia, p. 217.
} 
lo sensitivo o con la impresión de realidad. Como el sentir fue minusvalorado en general por el racionalismo y el idealismo, en comparación con la razón o la racionalidad y con la actitud puramente especulativa y teorizadora, es natural pensar que el surgimiento de un nuevo filosofar de un modo sistemáticamente unido a la realidad aprehendida impresivamente, era algo enormemente difícil desde los postulados habituales del pensamiento ilustrado e incluso del propio del siglo XIX. Si bien es cierto que Schopenhauer pensaba que los animales tienen inteligencia lo que refuerza de alguna forma la posible interacción de lo estimúlico con lo impresivo desde una perspectiva nueva que, como mínimo a mi juicio es dudosa. Una de las ideas más brillantes de la filosofía de Zubiri es la de la actualización intelectiva, ya que proporciona una comprensión de lo transcendental mucho más acorde con una concepción más moderna y actual de la reflexión filosófica y con un enfoque realista, descriptivo y fenomenológico, desde unos planteamientos plenamente metafísicos. De esta forma la actualización intelectiva de la realidad realizada por la inteligencia sentiente se convierte en el proceso fundamental que es analizado desde una perspectiva más objetiva, porque es más parecida a los procesos de observación característicos de los procedimientos de investigación científica, lo que le otorga un plus de mayor rigurosidad y profundidad algo siempre deseable en filosofía y en cualquier disciplina. Ciertamente la demostración de la actualización de lo real, es posible porque captamos o aprehendemos la realidad a través de los sentidos de un modo directo, aunque exista una distancia entre el sujeto que aprehende y lo objetivamente captado. Es indudable que existen diversas teorías de la ciencia vigentes en la actualidad que también pretenden demostrar con argumentos aparentemente plausibles sus afirmaciones. Las interpretaciones constructivistas, escépticas o anarquistas de la ciencia como la de Feyerabend, me parecen válidas en ciertos aspectos pero no en su totalidad. En relación con el constructivismo en teoría de la ciencia, pienso que lo fundamental es lo percibido o aprehendido por el sujeto que conoce y la elaboración constructiva de la inteligencia se fundamenta en la correcta y precisa aprehensión de lo real. Respecto a la filosofía de la ciencia de Feyerabend, su crítica de la racionalidad y de las técnicas argumentativas e incluso de la coherencia, señala en mi opinión que incluso el concepto de demostración, está al menos en cierto sentido siendo relativizado en el anarquismo metodológico en sus análisis sobre la ciencia y sus procedimientos, hipótesis y teorías. 
Que Zubiri ${ }^{3}$ insista en que «la diafanidad de lo transcendental determina la inteligencia» es significativo, ya que es verdad que la claridad última acerca de lo que es la realidad, si se reflexiona sobre la misma, es muy difícil de hallar. Lo diáfano aunque sea algo claro es interpretable y en esto está a mi juicio lo difícil y existen distintas interpretaciones posibles de lo que es la realidad, dentro de un realismo que se fundamenta en la aprehensión primordial. De todos modos, las cosas son para Zubiri la propia diafanidad y la unidad intrínseca entre las mismas y la inteligencia es lo diáfano. De este modo se reafirma y justifica claramente el realismo. Además la biología y las neurociencias aportan actualmente datos que aseveran la validez y justificación de una teoría realista del conocimiento como la zubiriana. El mismo Zubiri se apoya constantemente en sus escritos, en los conocimientos biológicos de su tiempo acerca de los procesos perceptivos e intelectivos. Y es que la potencia especulativa del intelecto humano aun siendo enorme, no alcanza resultados concluyentes en su proceso de búsqueda de los fundamentos del mundo y de lo real .El hecho de que Zubiri critique que la metafísica escolástica no haya analizado la cuestión de la diafanidad transcendental, es algo entendible desde el interés zubiriano por este nuevo enfoque acerca de la realidad en impresión como expresión de lo transcendental que es la realidad en impresión. Incuestionablemente como los planteamientos de los pensadores escolásticos se circunscribían a un campo de aspectos semánticos y conceptuales que derivaban del aristotelismo y en general de la filosofía griega antigua, lógicamente no estaban en condiciones de apreciar la necesidad de una nueva dimensión de la transcendentalidad vinculada profundamente a lo real o empírico sin una intención predicativa, categorizadora o logificadora. Por tanto, la metafísica puede considerarse como un saber de transcendentalidad, unido a la aprehensión de lo que es la forma o formalidad de realidad, y estando abiertos a los sentidos y significaciones o a lo que da que pensar la propia realidad a la mente humana, ya que el dar de sí de las cosas, que es una expresión que Zubiri usa en sus obras, es una imagen muy gráfica de lo que representa la actividad pensante de los seres humanos que no está disociada en modo alguno de la realidad, sino todo lo contrario. Como acertadamente indica Alejandro Llano ${ }^{4}$ : «la filosofía kantiana no se «preocupa» del conocimiento inmediato de las cosas, en cuanto reales, sino de la mediación operada por las condiciones que hacen posible el conocimiento». Si bien conviene tener en cuenta que

${ }^{3}$ ZUBIRI, X. (1994). Los problemas fundamentales de la metafísica occidental. Madrid: Alianza, p. 32.

${ }^{4}$ Llano, A. (2002). Fenómeno y trascendencia en Kant. Pamplona: Eunsa, p. 49. 
Kant afirma que hay dos categorías de lo real, una de cualidad y otra de modalidad. Respecto a la libertad tal como la entiende Kant, es cierto que afirma su realidad en sí por medio de la conciencia moral, siendo la realidad de la libertad uno de los fundamentos de la filosofía crítica. En efecto esta es la cuestión fundamental que está presente en el proceder del kantismo, ya que las condiciones intelectivas para el acceso cognoscitivo a lo real son de un orden que no es conceptual, puramente categórico o judicativo tampoco para Kant. Si permanecemos en el orden de las categorías, sin esquemas ni sensibilidad estas categorías carecen de un significado objetivo, real. Precisamente la filosofía zubiriana se opone al idealismo trascendental kantiano, desde un análisis descriptivo de cómo es el proceso perceptivo o aprehensivo de la mente. Que esto se traduce en un realismo radical y transcendental es evidente, si bien es necesario señalar que son posibles desarrollos de diferentes clases de realismo y de transcendentalismo, en el curso del devenir de la reflexión filosófica.

Ciertamente existen otras dimensiones de lo transcendental que son más dificilmente delimitables, ya que, como también escribe Ferraz Fayos ${ }^{5}$, en el planteamiento zubiriano Dios es ante todo «realidad absolutamente absoluta» que es posibilitante para el hombre.

Aunque conviene poner de relieve que Zubiri, con sus sutiles interpretaciones acerca de lo que es la inmanencia y la transcendencia referidas al mundo y a lo divino, destruye o volatiliza las concepciones tradicionales acerca de estas dos ideas dándoles una significación mucho más ambivalente. De este modo, el que Dios sea transcendente a la realidad, aunque de una forma muy especial, es la manifestación de que está fundamentando el que las cosas sean distintas a la naturaleza divina. Los problemas surgen si se pretende averiguar cómo es posible que el nivel puramente discursivo y especulativo sea suficiente para la explicitación de esta especie de enigma de la transcendencia divina, partiendo del supuesto previo de la existencia de la divinidad. Considero que como la transcendencia en el nivel espiritual y religioso, tal como la describe conceptualmente Zubiri, es enriquecedora para los seres humanos, ya que muestra entre otras cosas la accesibilidad de Dios y también su mundanidad, ya que, como dice Sáez Cruz $^{6}$ «esta deiformación como semejanza activa y dinámica con Dios es de

${ }^{5}$ Ferraz Fayos, A. (1988). Zubiri: el realismo radical. Madrid: Cincel, p. 221.

${ }^{6}$ SÁez Cruz, J. (1995). La accesibilidad de Dios. Salamanca: Univ. Pontificia, p. 287. 
carácter metafísico y no simplemente moral», lo que desde mi planteamiento es algo inequívocamente positivo, también desde actitudes agnósticas como la explicitada por Tierno Galván en su libro ¿ Qué es ser agnóstico? que tan claramente explicó la importancia de la propia finitud ante las dudas que pueden surgir en el pensamiento humano ante los grandes enigmas de la existencia, la libertad, la muerte, el sentido de la vida, etc. En este sentido el modelo de la perfección divina, exista o no, puede ser pragmáticamente útil en las circunstancias vitales de las personas y también en sus proyectos. Se percibe una clara similitud entre el raciovitalismo de Ortega y Gasset, sobre todo en lo que concierne a su perspectivismo y a su valoración de la mundanidad y de la realidad, y el realismo zubiriano.

Ciertamente puedo ofrecer argumentos abductivos que reafirman que la mejor explicación en relación con el entendimiento de lo que es la realidad, es precisamente una actitud realista como la zubiriana. Y lo es, porque la aprehensión sentiente e impresiva de las cosas de la realidad está basada en los datos de las ciencias naturales y de la neurociencias actuales que confirman la validez y justificación de lo afirmado por Zubiri. Existen también argumentos que confirman y demuestran la plausibilidad empírica de las aseveraciones zubirianas respecto de su realismo radical, ya que son más probables que su negación, ya que también otros pensadores como Ferraz Fayos, reiteran la base científica que está presente en el procedimiento creativo de la filosofía realista y transcendental de Zubiri.

Argumentando analógica o comparativamente, también se observa que existen razones para afirmar la justificación epistemológica y ontológica del realismo zubiriano. Otra cuestión diferente es que pueden desarrollarse distintos tipos de realismo, si bien Zubiri rechazó el realismo ingenuo. Desde mi perspectiva los argumentos que nos dan las ciencias sobre la coherencia de lo que Zubiri denomina intelección sentiente es una de las pruebas más claras para la afirmación de la validez de la metafísica intramundana zubiriana.

Otro argumento más que apoya la justificación y validez de la noología zubiriana es que reafirma que la inteligencia es el resultado sensitivo del sistema nervioso humano. Y es cierto que el contenido de cada imagen que se ve se siente como algo real. Además es evidente que la belleza de lo real potencia el gusto por lo real, algo que Zubiri tiene presente continuamente en su producción filo- 
sófica y en su realismo. Y es que como escribe Philibert $\operatorname{Secretan}^{7}$ : «Dándonos el gusto de lo real, Zubiri purifica nuestra mirada y fortalece esta sensibilidad inteligente, tan pacientemente analizada, que nos permite amar apasionadamente lo real y gustar hasta lo absoluto». En este sentido se comprende que su filosofía haya despertado entusiasmo ya que el campo de la realidad es inmenso y está abierto a la curiosidad humana de modo interminable. Como indica también Thomas Fowler: «La filosofía de Zubiri puede superar los graves problemas de las grandes teorías de la ciencia en el siglo XX. Todas ellas fracasan porque ignoran los tres niveles de la inteligencia humana y caen en la trampa de la logificación de la inteligencia». Porque la aprehensión, el logos y la razón son definidos, descritos y argumentados por Zubiri de un modo convincente que se fundamenta en análisis muy profundos y rigurosos acerca del proceso cognoscitivo humano y desde una base científica que sustenta sus sólidas argumentaciones. $\mathrm{Y}$ es indudable que el pensamiento zubiriano clarifica numerosas cuestiones importantes relativas sobre la ciencia, la teología y el conocimiento. Un motivo más para confirmar la utilidad de la filosofía o metafísica realista zubiriana.

Zubiri considera que la ciencia no es lo primero sino que debe basarse en la fuente primaria que es la aprehensión primordial. Como también argumenta Thomas Fowler «El logos y la razón no tienen que ir a la realidad o crearla; ellos nacen en ella y permanecen en ella. Cuando una cosa es conocida sentientemente, al mismo tiempo se conoce como una realidad». Lo que tiene como consecuencia que es necesario seguir un procedimiento metódico y no arbitrario como defendían los postmodernistas en la búsqueda de la verdad. Zubiri insiste en sus obras en que el conocimiento acerca de la realidad nunca está completo y está sujeto a revisión. La afirmación zubiriana de la apertura de la realidad y las limitaciones de la razón humana son en mi opinión razones poderosas para pensar que su orientación filosófica es valiosa. El mismo Zubiri decía que la filosofía no debe ser conservadora y consideraba que su gran aportación a la metafísica podía ser continuada con un desarrollo de sus planteamientos y desde otros diferentes.

\footnotetext{
${ }^{7}$ SeCretan, Philibert (2011). Guía Comares de Zubiri. Granada: Comares, p. 350.

${ }^{8}$ Fowler, Thomas (2011). Guía Comares de Zubiri, p. 390.

${ }^{9}$ Ibidem, p. 388.
} 
Otro argumento que a mi juicio es de peso para demostrar la utilidad y la importancia del realismo radical zubiriano es que usa una metodología fenomenológica de tipo descriptivo que proporciona buenos resultados en el análisis de lo que es la realidad. En lo relativo a lo que se denomina el paradigma de la inteligencia sensible que separa el sentir y el saber es necesario decir que esta presuposición es falsa. Como también afirma Thomas Fowler ${ }^{10}$ argumentando sobre Zubiri en el panorama de la filosofía de la ciencia del siglo XX: «No tenemos que inferir la realidad basada en datos que nos son entregados, como en el modelo de un sistema de tecnología de información con sensores remotos, porque estamos sumergidos en ella; el sentir y el saber son parte de un mismo proceso». En efecto, esto se está demostrando de modo continuo con las investigaciones de las neurociencias y la psicología cognitiva en la actualidad. Ciertamente la significación de lo que es sentir la realidad está integrada en la misma vida humana en la totalidad de sus aspectos ya que como también escribe Jesús Ramírez $\operatorname{Voss}^{11}$ : «En realidad de verdad es como las cosas tienen que ser entendidas. La realidad es un carácter de las cosas difícil de expresar. Prescindiendo de toda otra referencia, el sentir, escribe Zubiri, es realidad real». La identificación entre el sentir y la realidad es una de las cuestiones esenciales que proporcionan una dimensión plenamente moderna a la filosofía zubiriana y que la colocan sobre todo con su trilogía acerca de la Inteligencia sentiente, en unos niveles de reflexión comparables a los de Kant con su Crítica de la Razón Pura y con un alcance parecido. Ya que a diferencia de lo que pensaba el filósofo alemán, la intelección humana no es síntesis trascendental sino como dice Zubiri la simple actualización de lo real en la inteligencia sentiente .Otra razón más para mostrar la profundidad y valor de la filosofía realista zubiriana es su insistencia en impulsar la autorrealización humana. Algo que está en la línea de lo que también proponía Hegel con el cultivo del espíritu a través de la cultura y de la vida. Porque como escribe Jacinto Rivera de Rosales ${ }^{12}$ acerca de la Fenomenología del Espiritu : «El espíritu ha de salir de la naturaleza y alcanzar su realidad por medio de la Bildung, la cultura o cultivo del espíritu». Para Zubiri el desarrollo de las posibilidades humanas es el logro paulatino de la realidad deseada.

\footnotetext{
${ }^{10}$ Ibidem, p. 386.

${ }^{11}$ Ramírez Voss, J. (2011). Guía Comares de Zubiri. Capítulo: «La concepción de la lógica en el pensamiento de Zubiri», p. 327.

${ }^{12}$ Rivera de Rosales, J. (2010). Hegel. La Odisea del Espiritu. Capítulo: «El espíritu extrañado de sí mismo: la cultura». Madrid: Circulo de Bellas Artes, p. 258.
} 


\section{La consideración transcendental de la esencia}

Ciertamente que Zubiri afirme que la esencia es realidad es algo positivo porque coloca a la metafísica y noología zubiriana en un contexto argumentativo y metodológico radicalmente diferente del planteado por el racionalismo y el idealismo. En contra de los planteamientos hegelianos que como comenta respecto a la Ciencia de la Lógica, Félix Duque ${ }^{13}$, suponen que «Gracias a la lógica, la realitas del mundo deviene razonable y las ciencias unificables enciclopédicamente», la actitud filosófica de Zubiri es radicalmente distinta porque la comprensión de la realidad surge de la aplicación de la aprehensión de la inteligencia sentiente sobre lo real. Y es que como dice Zubiri ${ }^{14}$ la esencia incluye la existencia dentro de sí, «Para Soto, en efecto, entre esencia y existencia hay cuando menos, una distinción modal ex natura rei, de suerte que la esencia es tan sólo un momento de la realidad, aquel momento que ex natura rei prescinde de la existencia».Ya que la existencia en mi opinión, se fundamenta en lo real que es lo primero siendo la existencia una derivación posible de las condiciones empíricas de la realidad. De este modo, la metafísica zubiriana insiste de modo muy claro en la preeminencia de lo real y lo transcendental sobre lo existencial ya que lo incorpora internamente en la propia dimensión mundana de la realidad de las cosas. Otra cuestión distinta es que si bien la realidad es el fundamento del ser, la esencia no se afirme unívocamente de Dios. Ya que la imperfección de lo material y lo mundano no es comparable a la sustantividad plenaria atribuida por Zubiri a Dios desde su perspectiva cristiana. Para Zubiri, Dios está formalmente presente en el mundo y este es «donación personal» de la divinidad algo que si bien es entendible desde la religiosidad del gran pensador español, me parece que indica que parte de una concepción espiritualista que se aproxima algo a planteamientos de índole fenomenológica como es la donación de Jean Luc Marion ${ }^{15}$ ya que escribe: «Las dos operaciones consistentes en reconducir al Yo de la conciencia y en volver a las cosas mismas, lejos de contradecirse, marcan las dos vertientes del único libramiento de la reducción a la donación». En el caso de Marion la donación no es algo personal de Dios como en la metafísica zubiriana pero existe una cierta similitud porque ambos parten de procedimientos fenomenológicos que son perfectamente válidos en su acercamiento a la realidad. Que la onticidad de

\footnotetext{
${ }^{13}$ Hegel (2011). Ciencia de la Lógica. Vol. I. Madrid: Abada, p. 131.

${ }^{14}$ Zubiri, X. (1985). Sobre la esencia. Madrid: Alianza, pp. 459, 460.

${ }^{15}$ Marion, J. L. (2008). Siendo dado. Madrid: Síntesis, p. 51.
} 
las cosas pueda ser entendida como una manifestación de la donación, como se deduce de los escritos de Marion, me parece que es una explicación menos coherente respecto a cómo es la percepción o aprehensión de la realidad en los seres humanos. En este sentido la exposición discursiva y argumentativa zubiriana estimo que es más acorde con una interpretación del mundo y de lo real más sistemática y sobre todo más objetiva y atenta a la materialidad de las cosas del mundo tal como se presentan a los sentidos humanos.

Si bien es cierto que desde mi reflexión, el realismo se fundamenta transcendentalmente y la metafísica o filosofía también ya que el sistema filosófico zubiriano así lo muestra de un modo claro, entiendo que en la filosofía contemporánea se cuestione o discuta acerca de si el realismo admite una fundamentación transcendental. De hecho así lo plantea un artículo de Fernando Broncano Rodriguez. Y esta discusión acerca de la fundamentación transcendental, ya se basa en una actitud escéptica de principio, porque como es sabido, la epistemología para ciertos filósofos no tiene validez o ni siquiera interés, como es el caso de Feyerabend, Wittgenstein, Rorty, etc, lo que supondría la existencia de una era post-epistemológica. Considero que si son necesarias las reflexiones y consideraciones de la filosofía de la ciencia, ya que además de su utilidad metodológica refuerzan más todavía la función del pensamiento filosófico. Creo que Zubiri no estaría de acuerdo con la desaparición de la epistemología como lo demuestra su trilogía noológica sobre la inteligencia. Porque incluso la noología puede ser desarrollable desde las perspectivas de los nuevos filósofos que se interesen por la misma, con enfoque diversos en relación con su pensamiento original acerca de las cuestiones relativas a la teoría del conocimiento. Existe otra posición filosófica, que afirma un neotranscendentalismo y que se opone a la actitud absolutamente escéptica del anarquismo epistemológico de Feyarabend y en general a la posición post-epistemológica, y que considero coherente y en la que quizás se pueda encuadrar a la filosofía de Zubiri, si bien como un neotranscendentalismo especial, que puede servir para poner en comparación su transcendentalismo realista y metafísico con la neohermenéutica neotranscendentalista de pensadores contemporáneos como Apel, Davidson y Putnam.

Considero que son posibles desarrollos de diversas metafísicas intramundanas según modos de pensamiento y argumentación que siendo rigurosos y coherentes dan expresión a nuevos sistemas de reflexión que abran nuevas vías de comprensión respecto a la realidad y al ser humano. Lo que pueden parecer 
paradojas en el pensamiento zubiriano a mi juicio no lo son porque son el resultado de la aplicación de unos marcos semánticos y hermenéuticos que en mi opinión tienen que ser más amplios y estar abiertos a las innovaciones y a interpretaciones complejas. El ejemplo de la producción filosófica de Derrida me parece especialmente clarificador y lo señalo como contrapunto crítico ya que desde mi análisis la obra zubiriana no supera los límites del lenguaje cosa que si hace el deconstruccionismo derridiano sin que sea una crítica negativa al pensador francés.

\section{Reflexiones sobre transcendentalidad, fundamento, metafísica y realidad}

Ciertamente todas esta cuestiones relativas a la fundamentación transcendental de la metafísica están profundamente interrelacionadas también con la noología, la ética, la antropología y las restantes partes de la filosofía porque constituyen un sistema de ideas interconexionadas como es natural si se reflexiona sobre los vínculos conceptuales presentes en todo movimiento filosófico. Como indica Zubiri ${ }^{16}$ «Pero el sentir está precisamente constituido no por esta diversidad cualitativa, sino por la unidad del momento de formalidad, por la unidad de la impresión de realidad». Precisamente la inespecificidad es lo más significativo de cara a la determinación de lo más esencial de la realidad o del más o trans de lo que es aprehendido como contenido empírico real. En este sentido queda claro que la descripción de la realidad desde una perspectiva óntica y ontológica depende de lo se entiende que es la impresión de realidad y la intelección sentiente tal como la explicita la noología zubiriana .Es cierto que la transcendentalidad es interpretable como el plus de realidad de las cosas y es también de modo simultáneo el más de la forma de realidad que se capta o aprehende en las cosas del mundo. Por tanto la inteligencia humana posee un campo de aplicación que se centra fundamentalmente en lo real ya que es lo que afecta de modo directo todos los aspectos de la existencia humana en toda la multiplicidad de ámbitos que se puedan considerar. Como escribe Zubiri «Transcendentalidad es lo propio de un concepto en que lo concebido está en todas las cosas. Ser es el concepto más universal, común a todo. Los demás conceptos no son

${ }^{16}$ ZuBIRI, X. (1984). Inteligencia y realidad. Madrid: Alianza, p. 113. 
transcendentales, sino a lo sumo conceptos genéricos». Considero que la realidad está presente en todas las cosas del mundo por tanto es perfectamente coherente pensar que el concepto más universal que sustituye al de ser es precisamente el de realidad entendida también como transcendentalidad. Se puede pensar que si se interpreta la lógica trascendental como una teoría última de la ciencia, tal como indica Husserl, esto es aplicable a las reflexiones epistemológicas y metafísicas de modo general. Y es que el «ex» que para Zubiri equivale analíticamente a la impresión de realidad es la expresión del más o del trans de la cosa real ya que es indudable desde mi análisis que las cosas reales transcienden su contenido empírico y semántico actual en cuanto realidad abierta.

Como la significación y el campo semántico de la transcendentalidad es amplio porque comprende matices muy precisos en el sistema metafísico zubiriano es natural que diga que tiene cuatro momentos constitutivos. El primero expresa que cada nueva aprehensión o percepción de realidad se inscribe en la formalidad de realidad que es numéricamente la misma. Y esto es decisivo porque de esta manera se evita la creación artificial de muchas clases distintas de transcendentalidad que son innecesarias y que complicarían inútilmente la comprensión de la realidad. El segundo momento constitutivo de la transcendentalidad, incide sobre todo en la cuestión de la respectividad porque es verdad que la cosa real está abierta a sus propios contenidos y a lo real. La respectividad es la pura apertura de la formalidad de realidad. Y es comprensible que Zubiri afirme que la respectividad es en el fondo la gran articulación transcendental que constituye las cosas y que por tanto prácticamente sea casi lo mismo decir realidad que respectividad.

Respecto al tercer momento de transcendentalidad, conviene resaltar que la suidad de cada cosa o su contenido en propio, también es reificado en la formalidad de realidad y por tanto es un contenido claramente transcendental. El cuarto momento se revela si se considera el momento físico y mundanal de las cosas. Como dice Zubiri ${ }^{17}$ «En este respecto, cada cosa real es más que sí misma: es justo transcendental, tiene la unidad transcendental de ser momento del mundo. La formalidad de realidad es así «mundificante»: es el cuarto momento de la transcendentalidad, del ex». Además está claro que la inteligencia humana

${ }^{17}$ Ibid., p. 122. 
parte de la experiencia del mundo físico que constituye la realidad, lo que refuerza aún más la validez gnoseológica y ontológica del realismo transcendental zubiriano. De estas argumentaciones, se deduce que lo transcendental no es apriórico como pensaba Kant y que es necesario tener presente la dinamicidad y apertura de lo transcendental entendido como conjunto de caracteres de lo real como algo abierto a cambios, modificaciones, etc.

En la actualidad se puede pensar que el elenco de tipos de realidad ha aumentado y también es objeto de discusión, lo que se puede considerar como realidad y lo que no. Saber qué es la realidad es otra de las grandes y permanentes cuestiones que está de plena actualidad. La realidad virtual es otra de las dimensiones de la realidad que nos ofrece posibilidades reales antes prácticamente impensables o casi inimaginables. Si bien Zubiri hablaba de lo irreal que es algo equivalente en parte a lo virtual es indudable que la repercusión de lo imaginado, proyectado e ideado es crucial en la vida humana porque somos seres de proyectos ya que aunque vivimos en el presente estamos también lanzados al futuro que es algo irreal. De este modo, el dinamismo transcendental de la realidad afirmado por Zubiri se manifiesta de modo claro a mi juicio en la evolución ya que como indica el neodarwinismo existen cambios en las especies y además transformaciones en la naturaleza geológica del mundo aunque sea considerando escalas enormes de tiempo como es lógico. En este sentido estimo que estos cambios producen una transformación cósmica o mundanal por causa de los cambios talitativos en la naturaleza de las cosas y de los seres del mundo.

De hecho, la realidad, al menos tal como la entiende Zubiri, no fue considerada como el eje fundamental de la teoría del conocimiento en el empirismo británico ya que consideraba la impresión como simple afección subjetiva independiente de la alteridad de lo presentado y esto no es metafísicamente sostenible desde una perspectiva que estime de un modo mas profundo la significación de la presencia de las cosas o de lo empírico. Ya que como escribe Zubiri ${ }^{18}$ «La afección sensible envuelve la presentación de la alteridad de algo que en el caso del estímulo, será un mero signo objetivo y, en el caso del hombre es una realidad». Que la alteridad o lo otro de lo aprehendido posea carácter de realidad es lo decisivo en el caso de la intelección humana a diferencia de la animal. Y esto no fue suficientemente considerado por el empirismo inglés representado por

${ }^{18}$ ZubIRI, X. (2001). Sobre la realidad. Madrid: Alianza, p. 169. 
Locke y Hume porque entre otras razones no manejaban el concepto o la noción de realidad de una manera similar a la zubiriana ni tampoco con un sentido más parecido al actual o moderno. Por tanto es la sucesión de las cosas, de los estímulos, lo que pertenece al campo perceptivo y al campo de realidad. Lo que son de suyo las cosas de la realidad es indudable que está notablemente enriquecido por la tradición cultural acumulada presente en el campo perceptivo humano.

Ciertamente que Zubiri esté continuamente escribiendo sobre la realidad es un hecho innegable que justifica que su pensamiento sea caracterizado como realismo radical. Aunque también es cierto que cualquier sistema filosófico deja cosas sin explicar suficientemente porque la actividad reflexiva siempre plantea nuevos retos y nuevas aclaraciones del sentido de los términos y conceptos con lo que la tarea es interminable precisamente por causa de la riqueza del lenguaje natural y del artificial o técnico propio de la filosofía. Además el lenguaje objeto de la filosofía zubiriana aplicado a la realidad potencia e incrementa la capacidad crítica de la filosofía y de la ciencia. Que Zubiri afirme una actitud crítica sobre la realidad y la experiencia es la muestra palpable de que su metafísica es definible como un realismo crítico. De este modo, el criticismo realista zubiriano se integra perfectamente con los resultados de la ciencia ya que parte de los datos de la misma si bien profundiza por medio de reflexiones metafísicas en la naturaleza de la realidad y de lo que es lo real y el mundo para la persona, asuntos que son más especulativos que los específicos de la teorización científica.

Evidentemente como dice Javier Monserrat «La investigación sobre la esencia pretende formular aquello que es una cosa real. Pues bien, lo que Zubiri nos dice es que la esencia o cosa real es un sistema estructural de notas suficiente en el orden constitucional». Esto supone que el fondo primario de descripción está constituido por las propias notas de las cosas reales. Por tanto se observa en la actitud filosófica de Zubiri, una separación del procedimiento exclusivamente escolástico ya que la explicitación de lo que es la realidad y lo mundano requiere abundantes descripciones de las estructuras del mundo.

Que pueda atribuirse al pensamiento zubiriano las características fundamentales del pensar analéctico me parece algo claro por múltiples motivos y razones. Ya que si la actitud analéctica supone la jerarquización dialéctica de los seres y de la realidad y consecuentemente la ordenación sistemática de lo real de acuerdo con unas categorizaciones conceptuales muy precisas esto es lo que hace 
Zubiri con su metafísica transcendental. En este sentido se perciben en la filosofía zubiriana unos planteamientos metodológicos y analíticos claramente analécticos. Porque como también argumenta López Quintas ${ }^{19}$, «El discurso es el modo de situarse el hombre, a lo largo del tiempo y del espacio, en el plano de lo real que le compete. A la altura específicamente humana, toda discursividad debe ser intuitiva y toda intuición discursiva». De este modo, la intuición adquiere una significación decisiva ya que supone la negación de cualquier forma de de logificación de la inteligencia y también de la negación de la actitud conciencialista de la fenomenología husserliana, algo que por supuesto es perfectamente compatible con una utilización de la descripción fenomenológica pero de un modo diferente al que usó Husserl y que no está en la línea del pensamiento de Marc Richir que se basa más en lo prerreflexivo pero de una manera distinta a la propia de Zubiri que es probablemente más argumentativa y clásica. La actitud realista que es característica de Zubiri, es la expresión de un transcendentalismo que se manifiesta en la intuición acerca de qué es lo real y cómo es la realidad ya que como verdaderamente se alcanza la comprensión de lo que son las cosas de la realidad es a través de la impresión de realidad. Y lo impresivo es lo directamente intuido por los sentidos a través de la aprehensión o percepción de la inteligencia.

El transcendentalismo realista de Zubiri es el fundamento de la metafísica porque la realidad es el fundamento de todo. La utilización por parte de Zubiri de esquemas explicativos más bien circulares, me parece sobre todo útil para una mejor explicación del sentido exacto que da a sus vocablos, ya que los esquemas de desarrollo argumentativo lineales son menos sistemáticos y menos justificables conceptualmente. En la filosofía transcendentalmente realista, es claro que no es suficiente con la consideración eidética de lo real, algo con lo que estoy plenamente de acuerdo, ya que es absolutamente necesaria una perspectiva empírica o experiencial para acceder a un contacto directo con las cosas de la realidad. Y la metodología descriptiva y fenomenológica utilizada por Zubiri me parece la más adecuada, si bien es verdad también que son posibles otras descripciones y explicaciones de lo real en función de los intereses específicos e intenciones de cada filósofo y de su propia originalidad. De este modo el realismo zubiriano con su interpretación holista y estructural del mundo pulveriza los dualismos

${ }^{19}$ López Quintas, A. (1976). Realitas II. Madrid: Sociedad de estudios y publicaciones, p. 452. 
separadores y unifica la diversidad de las cosas reales en una consideración transcendental del mundo y del cosmos.

Como escribe López Quintás ${ }^{20}$ en relación con la actitud realista respecto al conocimiento «De aquí arranca la simpatía de Zubiri hacia las teorías que defienden el realismo de los universales, sin duda por la urgencia de ver en la realidad misma cuanto el entendimiento juzga decisivo en la intelección». Ya que el entendimiento es sentiente y las divisiones artificiales entre el sentir y el inteligir no son convenientes para la aprehensión adecuada de la realidad. Porque los contenidos mentales derivan en buena medida de la captación, aprehensión o percepción de lo empírico si bien desde mi punto de vista también interviene de forma clara la actividad combinatoria, analítica e imaginativa del intelecto. Es cierto que el sentir tiene una importancia capital en todo proceso cognoscitivo como también indica López Quintás ${ }^{21}$ «Zubiri se cuida de subrayar que el sentir íntimo implica el logos que dicta lo que hay que decir. Es la voz de las cosas». En mi opinión, esta imbricación absoluta entre el sentir, el logos, la realidad y consecuentemente la transcendencia es la manifestación más clara y evidente de que la transcendentalidad es el auténtico fundamento de la metafísica. Porque las posibilidades que ofrece a la evolución y desarrollo del pensamiento filosófico lo transcendental son innumerables porque dependen de la diversidad de pensadores que quieran transitar por la vía que abre un transcendentalismo genérico de tipo realista.

Es evidente que un trascendentalismo idealista como el kantiano no alcanza el de suyo de las cosas o la auténtica realidad, cosa que si logra la metafísica realista zubiriana. Y es que en relación con la trascendencia elaborada por Kant como también dice Alejandro Llano ${ }^{22}$ «Es bien sabido que Hegel criticó duramente la concepción kantiana de las categorías. Como dice en la Ciencia de la Lógica, Kant nos presenta las formas a priori del entendimiento como algo que se ha encontrado en alguna parte».Y es que la sensibilidad a diferencia de lo que consideraba Kant si es intelectiva lo que marca una de las diferencias fundamentales respecto a un dualismo entre lo fenoménico y la cosa en sí que desde una perspectiva realista actual no es coherente. En este sentido la metafísica consi-

\footnotetext{
${ }^{20}$ Ibid., p. 465.

${ }^{21}$ Ibid., p. 467.

${ }^{22}$ Llano, A. (2002). Fenómeno y trascendencia en Kant. Pamplona: Eunsa, p. 99.
} 
dero que debe dedicarse fundamentalmente a la investigación, análisis y discusión de todas las cuestiones referidas a la realidad y también a las relativas a la antropología y a la ética que son las que quizás poseen mayor interés en el mundo contemporáneo por múltiples razones sobre todo desde la perspectiva de la reflexión filosófica.

Aunque el conocimiento del pensamiento escolástico por Zubiri era amplio y no cabe duda que influyó en alguna medida en la elaboración de su metafísica y noología, esto no impidió que desarrollase su propio transcendentalismo realista que se aparta completamente del enfoque escolástico. Ya que es cierto que las matizaciones que elabora sobre la clásica teoría de los transcendentales es algo interesante desde un punto de vista especulativo, no es lo decisivo en su realismo. De todos modos es cierto que uno de los pensadores que probablemente más se aproxime a algunos aspectos del pensamiento zubiriano es Suárez. Este afirma en sus Disputaciones Metafísicas, que lo esencial de una cosa individual no se distingue realmente de ella lo que está a mi juicio en una línea de pensamiento parecida a la zubiriana ya que el de suyo posee rasgos similares a esta consideración de la cosa individual. Ciertamente Zubiri se propuso la tarea de elaborar una metafísica de la individualidad algo que la metafísica suareciana no alcanzó a vislumbrar enredada en su compleja red de distinciones conceptuales. Y en mi opinión, uno de los puntos cruciales es que lo individual no depende de lo universal o general sino que se sustenta en sí mismo, algo que reafirma la filosofía zubiriana acertadamente y que la propia de Suárez no consideraba del mismo modo. No es necesario que el individuo lo sea desde la especie como consideraba la Escolástica.

La vinculación a la realidad de la filosofía se convierte en algo muy claro si simplemente se consideran algunos de los términos esenciales de la metafísica zubiriana como es el prius. Ya que las cualidades reales de cada cosa o la nota de cada objeto aprehendido posee una especificidad real que es lo que expresa su estar en la realidad. De todas formas que la metafísica debe estar fundamentada en la impresión de realidad entendida como lo transcendental es lo que hace posible una mejor y mayor clarificación de la multitud de cuestiones filosóficas que son objeto de la interrogación y reflexión humana. En este sentido la sistematicidad de la metafísica transcendentalista de Zubiri está en la línea de lo que propone uno de los grandes sistematizadores del pensamiento metafísico del siglo XVIII que es Wolff que como señala $\mathrm{M}^{a}$ Luisa P. 
Cavana $^{23}$, afirma que «finalmente he conseguido ordenar todo el conjunto, de tal modo que cada cosa es entendida y conocida por medio de lo demás, y así he hecho de la Metafísica un sistema, porque todas las doctrinas están en conexión». Otra cuestión diferente es la plena libertad que como es natural rige en la elaboración de los conceptos de cualquier sistema filosófico pero desde una actitud rigurosa en la argumentación y justificación de las ideas afirmadas.

La fundamentación transcendental de la metafísica que considero haber justificado y argumentado suficientemente sirve de base también a una diversidad de aspectos que están presentes en la filosofía de Zubiri. Y esto se debe al interés por abarcar la totalidad de dimensiones que conforman la realidad humana. Por tanto, es claramente pensable, que como escribe Pintor Ramos ${ }^{24}$ «A lo que está directamente religado el hombre no es a Dios, como a veces se ha interpretado, sino a la realidad en tanto que lo funda, le da poder para desplegar sus posibilidades y le confiere fuerza». De este modo la realidad captada en aprehensión primordial considero que es el fundamento de lo que es la transcendentalidad tanto referida a la propia metafísica como a la actitud reflexiva general del ser humano. Lo transcendental ha sido tratado por numerosos filósofos con enfoques diferentes al propio de Zubiri, como es el caso de Gustavo Bueno que con su materialismo filosófico introduce como escribe Hevia Echevarría $^{25}$ «la Idea de Materialidad Transcendental, a la que llegaría dialécticamente, por regresión a través de las contradicciones entre las partes del mundo, esto es, como trituración de toda formación mundana». Está claro que tanto Zubiri como Gustavo Bueno defienden la defensa de un plano transcendental si bien las diferencias acerca del contenido del mismo son notables. Incluso el parecido formal entre el sistema ontoteológico de Cayetano con el desarrollado por Bueno es una muestra más de que Zubiri no es una excepción en este contraste dialéctico con la Escolástica.

Que el mundo es entendido por Zubiri como carácter de realidad es lo más adecuado porque de este modo se pone de manifiesto que la unidad física de lo real es lo mundano en su más profunda consideración analítica. Ya que como

${ }^{23}$ P. CAVAnA, Mª Luisa (1995). Chr. Wolff. Madrid: Ediciones del Orto, p. 34.

${ }^{24}$ Pintor Ramos, A. (1995). Zubiri. Madrid: Ediciones del Orto, pp. 49,50.

${ }^{25}$ Hevia Echevarría, J. A. (ed.) (2005). Cayetano. Tratado sobre la analogía de los nombres. Tratado sobre el concepto de ente. Oviedo: Pentalfa Ediciones, p. 36. 
dice Marquínez Argote ${ }^{26}$ «Estas consideraciones permiten a nuestro pensador explicitar el sentido preciso que tiene para él la metafísica. El «trans» del orden transcendental remite al «meta» del vocablo metafísica». Y a mi juicio precisamente lo que está más allá de lo físico se fundamenta en la reflexión acerca de los sentidos de lo real o material. Por tanto incluso desde una perspectiva religiosa como la que tuvo Zubiri considero que es posible también basarse en la realidad del mundo y en su interpretación y comprensión a través de la inteligencia para el logro de nuevos conceptos que nos aproximen cada vez más a lo más profundo de nuestra percepción y entendimiento de lo que es la realidad que es un proceso inagotable en el tiempo. Gran parte de las aporías y de las dificultades de la filosofía fenomenológica actual y también de los otros movimientos filosóficos existentes actualmente provienen de la extrema dificultad para acceder a lo que es en su esencialidad el mundo o la realidad. Y esto es así en buena parte por las diversas formas de aplicar el intelecto al descubrimiento de lo prerreflexivo, de la intuición y de la aprehensión de lo dado.

De todos modos la orientación filosófica zubiriana se fundamenta en principios estructurales y constitutivos frente a los principios causativos aristotélicos y a su concepción de la sustancia. Ya que si a una realidad le quitamos todas sus notas no encontramos ningún sujeto oculto tras las mismas algo que niega el planteamiento sustancialista de Aristóteles y que Zubiri indica de forma muy coherente desde un planteamiento más profundo ontológicamente. Así se logra la transformación del sustancialismo en un sustantivismo que está absolutamente vinculado a una valoración de la estructura de la realidad algo que como también afirma Ellacuría es una de las razones de la radical novedad metafísica del pensamiento zubiriano. Que la esencia es lo estructurante y estructural de la realidad es evidente ya que lo real es objeto de investigación por medio de la reflexión acerca de lo que es la fundamentalidad de la propia realidad. Además pienso que lo transcendental representado por un nuevo concepto de realidad es el elemento diferenciador de las diversas metafísicas posibles. Algo que es muy original y que considero que señala un punto de inflexión en la historia de la metafísica y que estimo que debe ser más valorado por otras corrientes o movimientos filosóficos contemporáneos.

${ }^{26}$ MarquíneZ, G. y NiÑo, F. (2009). Introducción a la filosofía de Xavier Zubiri. Bogotá: Editorial el Búho, p. 61. 
El punto esencial para la delimitación más precisa del problema de la relación del sujeto cognoscente con lo real aprehendido es que el yo o la inteligencia sentiente desde su formalidad intelectiva pretende actualizar el no yo usando la terminología fichteana pero es cierto que primeramente lo actualiza como realidad. Además existe en la filosofía zubiriana una comprensión de que la actividad concipiente no es lo más fundamental en el proceso del conocimiento ya que la impresión de realidad es una de las bases que sustenta la actividad especulativa del intelecto. Porque es innegable que si la índole formal de la intelección es actualización se puede decir que la ideación, conceptualización y predicación son operaciones derivadas de la acción de la inteligencia sentiente. Puesto que la verdad se fundamenta en la intelección de la cosa ya que lo empírico es lo que sustenta la actualización de lo real en la mente. Que la fundamentación de la metafísica en lo transcendental abarca o comprende todos los conceptos explicitados en sus libros por Zubiri es algo que me parece claro. Porque la interconexión de todas sus ideas en un todo sistemático es lo que expresa la función esencial que posee su transcendentalismo como eje vertebrador o configurador de su realismo radical. No es extraño por tanto que exista una cierta dificultad en explicar lo que es de suyo de un modo exclusivamente conceptual o puramente especulativo ya que es necesario partir de la consideración de la aprehensión primordial y de la actualización de lo presente a la inteligencia. Ya que como el de suyo es el modo como la cosa real se presenta a la inteligencia ya no tiene sentido pensar en la unidad del ser como referencia de la intelección.

Evidentemente desde San Agustín hasta Hegel la metafísica se ha construido desde premisas y supuestos formalmente teológicos si bien es cierto que con la influencia de la filosofía platónica y aristotélica fundamentalmente.Y que el objeto de investigación de la filosofía es intramundano o empírico, al menos en buena medida es la expresión de la importancia y transcendencia de lo facticidad del mundo y de la realidad humana. Como escribe Zubiri ${ }^{27}$ «La seriedad del diálogo y la penosidad del discurrir, sólo son posibles por la sustancia de las cosas». Algo que determina la afirmación de que la realidad precede al ser lo que supone la superación de la hermenéutica heideggeriana y la construcción progresiva de un realismo a lo largo de su evolución filosófica como pensador. La reflexión socrática, por ejemplo, es a mi juicio una muestra de la importancia de

${ }^{27}$ Zubiri, X. (1999). Naturaleza, Historia, Dios. Madrid: Alianza, p. 240. 
la actitud dialógica y también del esfuerzo que supone la consideración rigurosa de los múltiples aspectos de la realidad. Ya que a diferencia de la actitud de los sofistas, el planteamiento de la mayéutica de Sócrates es un método de averiguación de lo que es el mundo y el ser humano pero desde el rigor en la argumentación y la contrastación con lo que es efectivamente la realidad. También se entiende que Diego Gracia ${ }^{28}$ escriba que «El hombre posee una función gracias a la cual queda por un lado, referido a las cosas, pero rebota, por otro, sobre ellas, llevándose consigo algo que no se identifica con la realidad física de estas últimas. Es el pensar». En efecto, esto es lo característico de la inteligencia humana que está sujeto como es natural a numerosas diferencias interpretativas en la comprensión de lo que es la realidad lo que da origen a los diversos movimientos filosóficos y a las diversas doctrinas o sistemas filosóficos existentes.

Ciertamente, los datos de la realidad no deben ser sometidos a la epojé, sino que son la manifestación de la unidad radical del sentir intelectivo algo que no había sido considerado por las diversas corrientes de la fenomenología. Lo que Husserl no consideró es que el momento material o bilético de la conciencia perceptiva como residuo fenomenológico una vez quitada la intención, no recoge la real significación de la sensibilidad humana o del propio sentir. Ya que este no es solo la identificación material de lo real sino también la función de presentificación y actualización de las cosas reales a la inteligencia. Y es que tanto Husserl como Heidegger, enfatizan la función ideativa y judicativa de la inteligencia en detrimento de la interpretación de las cosas reales como portadoras de inteligibilidad que es lo que propone la actitud realista zubiriana.

Lo óntico es lo primario a mi juicio ya que la pregunta por la realidad de las cosas es más esencial que la ontológica por el sentido del ser. Ya que ésta es claramente más interpretativa y especulativa que la valoración reflexiva de lo propiamente real tal como es aprehendido por los sentidos. Es natural por tanto que para Zubiri, lo radical sea la cuestión metafísica de la realidad de la que derivan tanto el problema ontológico como el hermenéutico. Y esto se expresa en toda su producción filosófica de modo que la estructuración de las cosas de la realidad es la plenitud de algo en el despliegue de sus notas. Ya que es cierto que

\footnotetext{
${ }^{28}$ GRACIA, Diego (1979). «La historia como problema metafísico» Realitas III-IV. Madrid: Sociedad de estudios y publicaciones, p. 88.
} 
se debe evitar cualquier actitud conciencista a la que podría conducirnos el término presencia, porque el inteligir humano es actualización de realidad.

Que la filosofía zubiriana pueda ser calificada como pura, me parece bien porque refleja un interés radical y profundo en su búsqueda de la verdad en todos los ámbitos de la realidad y del ser humano. Como escribe Suances Marcos ${ }^{29}$ en relación con la filosofía griega antigua. «El hombre griego se enfrentó, pues, de manera inmediata, a las cosas, pero, invirtiendo la dirección de la mirada inmediata, vio, en las cosas visibles una dimensión que las trascendía». Esta dimensión puede pensarse que es el principio de realidad, ya que si bien lo que fundamenta los modos cambiantes del aparecer de las cosas podría considerarse que es un principio inmaterial o divino aunque estimo que es más coherente pensar que la verdadera realidad sea precisamente la forma de lo real presente en todas las cosas del mundo. Ya que la duplicidad de realidades afirmada por Platón supone que es necesario trascender el mundo para acceder a lo real algo que no es necesario como también indica Zubiri y que es la confirmación de la transcendencia de la realidad aprehensible por el hombre. Lo que pone de manifiesto la transcendencia es la propia aprehensión directa de lo real. Por otra parte, que la formalidad de realidad es una de las cuestiones decisivas que desarrolla Zubiri en su filosofía es indudable. Es lo que hace posible que el carácter de realidad supere la estricta dimensión empírica de las cosas de la realidad. Y esto sucede porque los sentidos de lo real son comprendidos por los seres humanos y son el fundamento o la base de sus ideas que están en relación con el campo de realidad en el que viven y piensan, algo que fue olvidado o no considerado por la filosofía anterior a la filosofía zubiriana. Porque escribe Zubiri ${ }^{30}$ que «impresión de realidad podría hacer pensar que a la impresión de rojo o de caliente se añade una impresión más, la impresión de realidad. Pero esto es absurdo. Impresión sensible es siempre y sólo contenido en formalidad». Y esto es algo que no había sido realizado por el empirismo de Locke y Hume y tampoco por el sensismo de Condillac y de otros pensadores de la Ilustración. Que la vida humana se sustenta en la riqueza o abundancia de realidades es algo evidente y por tanto el reconocimiento de la transcendencia en lo real es la reafirmación de la validez y justificación de un nuevo enfoque de la ontología y de la teoría del

\footnotetext{
${ }^{29}$ Suances Marcos, M. (2006). Historia de la Filosofía Española Contemporánea. Madrid: Síntesis, p. 411.

${ }^{30}$ ZuBIRI, X. (1984). Inteligencia y realidad. Madrid: Alianza, pp. 63,64.
} 
conocimiento que es el propuesto por Zubiri en sus obras. Que la impresión de realidad refuerza la función judicativa del logos aplicado a la realidad es algo que conviene poner de manifiesto porque es un modo más de tener presentes las inmensas posibilidades del transcendentalismo entendido de modo realista sin negar la potencia especulativa del idealismo alemán que representa una fase brillante de la historia de la filosofía. Porque es evidente que la filosofía de la naturaleza de la filosofía idealista de Schelling o Hegel responde a unos presupuestos espiritualistas y mágicos que no son coherentes siendo en el fondo el resultado de un desconocimiento de determinadas explicaciones científicas acerca de la propia naturaleza que en su época no habían sido descubiertas.

En mi opinión, la transcendentalidad de lo real es lo que fundamenta la metafísica porque los sistemas filosóficos están en relación directa con la realidad, ya que ésta es su referencia principal. En claro desacuerdo con lo que plantea Apel ${ }^{31}$ en contra de una «explicación óntica del mundo», considero que es absolutamente necesaria para la clarificación de las cuestiones más difíciles de una metafísica realista. Ciertamente la aproximación del logos tal como lo utiliza Zubiri a una especie de razón argumentativa me parece adecuada si bien esto implica la aceptación de la discusión argumentativa como una vía más de investigación y matización de conceptos en el ámbito de la filosofía.

Mi propuesta filosófica se inscribe en lo que denomino transcendentalismo estético que consiste en un reforzamiento de la función de la contemplación reflexiva acerca de las múltiples dimensiones de la realidad. Lo que a mi juicio está en una línea parecida a la afirmada por Víctor Tirado San Juan que entiende al ser humano como ser activo en el dinamismo de la verdad y de la libertad y que está convencido de que la existencia moderna es estética porque es productiva como indica en «La dimensión estética de la realidad. ¿Cómo puede pensarse lo estético desde Zubir?»» Ya que la búsqueda de la verdad en filosofía es algo que se puede lograr también con la ciencia y la tecnología pero sobre todo con una actitud creativa y de perfeccionamiento constante de lo que se saber o conocer. Puesto que la interrelación entre la sensibilidad y el arte es completa considero que uno de los retos actuales es precisamente desarrollar una estética o actitud transcendental pero en un sentido completamente distinto al kantiano.

31 ApeL, Karl-Otto (2002). Semiótica trascendental y filosofía primera. Madrid: Síntesis, p. 49. 
Ya que como también escribe Daniel Innerarity ${ }^{32}$,»una filosofía entendida como arte de trabar y remitir, establecer vecindades y tejer vectores de sentido, consiste en que amplía el espacio situado entre la excesiva abstracción y la inmediatez irreflexiva». Efectivamente este transcendentalismo estético se basa en una actitud fundamentalmente crítica e interpretativa, que también depende de la espontaneidad del pensar y de un planteamiento imaginativo ante los retos del conocimiento y de la vida. Aspectos como la pasión, los sentimientos forman parte de la subjetividad de la filosofía y la enriquecen, no disminuyen su potencia argumentativa que está referida a lo real en toda su amplitud. La contraposición entre estética y racionalidad no es coherente porque si se profundiza en la reflexión se observa que lo estético es la ampliación de los aspectos de lo que se puede apreciar, valorar y entender con los sentidos y la inteligencia. La importancia de la experiencia es algo que en mi opinión también es necesario integrar en una adecuada interpretación de lo que puede ser un transcendentalismo estético, que englobe no tanto las ilusiones de una cultura posmoderna, que está cada vez más en la línea de lo ilusionante y ficticio sino que impulse a los seres humanos para que incrementen la experiencia propia como modo de alcanzar un conocimiento más confiable y cierto de lo que es la realidad. Incluso es posible una fenomenología transcendentalista estética que desde un punto de vista descriptivo analice la realidad en toda su complejidad. Además como la reflexividad está en relación con el mundo vital es evidente que depende de la historicidad del mundo, del saber, etc.

Ciertamente contra lo que pudiera parecer en una primera consideración, la filosofía, el arte y la actitud de contemplación estética están dirigidos a la realidad. No en vano, filósofos como Hegel y Schelling han dedicado sus esfuerzos a la elaboración de una filosofía del arte que completaba su sistema filosófico.

De todos modos, es evidente que el realismo transcendental de Zubiri es esencial porque es el que define el cambio de orientación de la filosofía contemporánea, que si bien es cierto que con el materialismo filosófico de Bueno tiene otra vía de desarrollo en el futuro estimo que las diversas fenomenologías existentes en la actualidad también son provechosas para una mayor discusión de ideas y un mayor debate conceptual a todos los niveles.

${ }^{32}$ INNERARITY, Daniel (1995). La filosofía como una de las bellas artes. Barcelona: Ariel. Barcelona, p. 17. 
La recuperación de lo que es auténticamente la realidad ha sido realizado por Zubiri con sus argumentaciones acerca de la transcendentalidad y fundamentalidad de la metafísica y de un modo especialmente brillante. El constructivismo zubiriano resultado de la aplicación de las afirmaciones del logos a los hechos puros dados en la aprehensión es una muestra más del gran sistema realista que articuló Zubiri en su afán por delimitar rigurosamente el ámbito epistemológico de su filosofía de la ciencia que tiene un cierto parecido en algunos puntos con la epistemología de Popper y Duhem.

Que el continuo contacto con la propia realidad es lo decisivo en la filosofía contemporánea me parece evidente. Y que el fundamento en lo real, de la ontología y por extensión de la metafísica no debe ser un simple juego verbal puramente abstracto y especulativo sino que debe estar en directa relación con el mundo y con la aprehensión sentiente de las cosas me parece indudable. Esto no supone que no sea conveniente el uso de la abstracción ya que esta es un procedimiento habitual de la filosofía en el análisis de lo real. Incluso el deconstruccionismo de Derrida es útil entre otras cosas, para una reflexión más amplia y profunda sobre la función del lenguaje en la argumentación filosófica. Por tanto creo que el eclecticismo tanto en filosofía como en ciencia me parece provechoso para la elaboración de un transcendentalismo estético que tiene su punto de partida en el realismo fenomenológico y transcendental zubiriano.

De todos modos es indudable a mi juicio que la actitud especulativa, estética y creativa característica de la reflexión humana y de la ciencia es necesaria en la época actual ante los nuevos desafíos a que se enfrenta el mundo en el presente y en el futuro.

\section{Agradecimientos}

Agradezco el apoyo mostrado respecto a mi artículo por la revista ÉNDOXA y también a la UNED por su inmensa labor formativa y de estímulo de la investigación y la creación. 


\section{Bibliografía}

Apel, K. O (2002). Semiótica trascendental y filosofía primera. Madrid. Editorial Síntesis.

Ferraz Fayos, A. (1988). Zubiri: el realismo radical. Madrid: Editorial Cincel.

Hegel (2011). Ciencia de la Lógica. Vol. I. Madrid: Abada editores.

Hevia Echevarría, J. A. (ed.) (2005). Cayetano. Tratado sobre las analogías de los nombres. Tratado sobre el concepto de ente. Oviedo: Pentalfa ediciones.

Gracia, D. (1979). «La historia como problema metafísico», Realitas III-IV. Madrid: Sociedad de estudios y publicaciones.

- (2008). Zubiri ante Heidegger. J. A. Nicolás y R. Espinoza (eds.). Barcelona: Editorial Herder.

InNERARITY, D. (1995). La filosofía como una de las bellas artes. Barcelona: Editorial Ariel.

López García, J. M. (2007). José Gaos y la filosofía coetánea. Oviedo: Ediciones Eikasía.

López Quintas, A. (1976). Realitas II. Madrid: Sociedad de estudios y publicaciones.

Llano, A. (1988). Fenómeno y trascendencia en Kant. Pamplona: Eunsa.

Marion, J. L. (2008). Siendo dado. Madrid: Editorial Síntesis.

MarquíneZ, G. Y Niño, F. (2009). Introducción a la filosofía de Xavier Zubiri. Bogotá: Editorial el Búho.

Nicolás J. A.; R. EspinOZa (2008). Zubiri ante Heidegger. Barcelona: Editorial Herder.

P. Cavana, Ma Luisa (1995). Chr, Wolff. Madrid: Ediciones del Orto.

Pintor Ramos, A. (2006). Nudos en la filosofía de Zubiri. Salamanca: Universidad Pontificia de Salamanca.

- (1995). Zubiri. Madrid: Ediciones del Orto.

Ramírez Voss, J. (2011). Guia Comares de Zubiri. Granada: Editorial Comares. Edición de Juan Antonio Nicolás. Capítulo: «La conquista de la lógica en el pensamiento de Zubiri».

Rivera de Rosales, J. (2010). Hegel. La Odisea del Espiritu. Madrid: Ediciones Círculo de Bellas Artes. Capítulo: «El espíritu extrañado de sí mismo: la cultura».

SÁez Cruz, J. (1995). La accesibilidad de Dios: su mundanidad y transcendencia en X. Zubiri. Salamanca: Publicaciones Universidad Pontificia de Salamanca.

Sartre, J. P. (2003). La trascendencia del Ego. Madrid: Editorial Síntesis. 
SOLARI, E. (2010). La raíz de lo sagrado. Contribuciones de Zubiri a la filosofía de la religión. Santiago de Chile: Ril editores.

Suances Marcos, M. (2006). Historia de la Filosofía Española Contemporánea. Madrid: Editorial Síntesis.

Tirado San Juan, V. (2010). «La dimensión estética de la realidad. ¿Cómo puede pensarse lo estético desde Zubiri?», Revista di Filosofía Iberica e Iberoamericana, Firenze (Italia), pp. 63 a 78.

ZuBIRI, X. (1994). Los problemas fundamentales de la metafísica occidental. Madrid: Editorial Alianza.

- (1985). Sobre la esencia. Madrid: Editorial Alianza.

- (2001). Sobre la realidad. Madrid: Editorial Alianza.

- (1984). Inteligencia y realidad. Madrid: Editorial Alianza.

- (1999). Naturaleza, Historia, Dios. Madrid: Editorial Alianza.

Recibido: 9/12/2011

Aceptado: 16/03/2012 